\title{
Association of transthyretin and nutritional status in patients with cancer
}

\begin{abstract}
Background: The malnutrition is generally seen in the hospital environment and it is a serious potentially condition in cancer patients. Measurement of serum proteins can be a useful indicator in the evaluation of nutritional status.

Objective: To evaluate the association of transthyretin with nutritional status in cancer patients.

Methods: This is a cross-sectional study, conducted with patients with a cancer confirmed diagnosis. Nutritional status was defined by the Subjective Global Assessment, anthropometric measurements, serum albumin and transthyretin.

Results: Seventy patients were evaluated, the median age was $58.51 \pm 14.85$ years, $51.4 \%(n=36)$ were elderly and female. Cancer of the lower gastrointestinal tract was the most prevalent, affecting $42.9 \%(n=30)$ patients. Subjective Global Assessment, transthyretin and serum albumin showed that $71.56 \%(n=50), 50.0 \%(n=35)$ and $32.9 \%(n=23)$ patients were malnourished, respectively. There were no differences between them. Significant correlations were found between transthyretin, arm circumference $(p=0.025)$, arm muscle circumference $(\mathrm{p}=0.008)$ and corrected arm muscle area $(\mathrm{p}=0.001)$. Transthyretin showed sensitivity of $58.0 \%$, specificity of $70.0 \%$, positive predictive value of $83.0 \%$, and negative predictive value of $61.0 \%$.
\end{abstract}

Discussion: The findings showed the association of transthyretin with the anthropometric variables used to evaluate nutritional status, especially those that evaluate the reduction of energy and protein reserves.

Conclusion: Transthyretin was moderately associated with anthropometric variables. Given the limitations, transthyretin may be a complementary tool in nutritional evaluation, because it is feasible, easy to interpret and undergoes changes in a short period.

Keywords: nutritional assessment, subjective global assessment, malnutrition, transthyretin, cancer
Volume 9 Issue 3 - 2018

\author{
Marina Abelha Barreto,' Ágata Depolo \\ Echebarrie,' Letícia Ribeiro Carvalho,' \\ Betullya Lucas Almeida,' Emanuella \\ Mardegani Batista Lima,' Tatiana Salgado \\ Toniato,' Katarina Papera Valente, ${ }^{2}$ Glenda \\ Blazer Petarli, ${ }^{1,3}$ Valdete Regina Guandalini' \\ 'Health Sciences Centre, Federal University of Espirito Santo, \\ Brazil \\ ${ }^{2}$ Postgraduate Student of Nutrition and Health, Federal \\ University of Espirito Santo, Brazil \\ ${ }^{3}$ University Hospital Cassiano Antônio Moraes, Brazil
}

Correspondence: Valdete Regina Guandalini, Federal

University of Espirito Santo, Avenue. Marechal Campos, I468Maruipe, 29040-090/Vitoria, ES, Brazil, Tel +55-279-9777-8404, Email valdete.guandalini@ufes.br

Received: June 10, 2018 | Published: June 25, 2018
Abbreviations: $\mathrm{AC}$, arm circumference; ACM, arm muscle circumference; BMI, body mass index; CAMA, corrected arm muscle area; CC, calf circumference (CC), CRP, C-reactive protein; NRS2002, Nutrition Risk Screening; TAPM, thickness of the adductor pollicis muscle; TSF, triceps skinfold; SGA, Subjective Global Assessment

\section{Introduction}

The magnitude of cancer is accompanied by the high prevalence of malnutrition, which accounts for $40-80 \%$ of patients with neoplasm. ${ }^{1,2}$ The nutritional status of the cancer patient is closely related to the quality of life and the prognosis of the disease, ${ }^{3}$ since malnutrition is associated with lower response and tolerance to antineoplastic treatment, infectious complications, increased hospital stay time and mortality. ${ }^{4,5}$

The nutritional evaluation of the oncological patient becomes essential to identifying the nutritional risk and to provide an early and adequate intervention. ${ }^{6}$ In clinical practice, the use of recognized instruments, such as the Subjective Global Assessment (SGA) and Nutrition Risk Screening (NRS-2002) are recommended, however they are subjective methods of nutritional assessment and may limit intervention reflexes and nutritional changes as they depend on the evaluator's accuracy and experience. ${ }^{6,7}$
Complementary methods, such as the measurement of serum proteins, have been used to identify malnutrition quickly and efficiently, since they provide indirect information on visceral protein levels such as albumin and transthyretin, considered important tools for assessing nutritional status. ${ }^{8}$

Transthyretin has a half-life of 2 to 3 days, and its serum levels decrease in response to liver disease, hydration status, hyperglycemia, acute and chronic inflammation and inadequate caloric-protein intake. ${ }^{9,10}$ Transthyretin is able to better identify patients at nutritional risk due to reduced food consumption rather than those already malnourished. ${ }^{9}$ Under conditions in which malnutrition may develop in a short time, transthyretin has become a preferred biomarker for assessing nutritional status when compared to the traditionally used albumin marker, which has a half-life of 21 days. ${ }^{10}$

Among the major proteins synthesized in the liver, transthyretin is a negative acute phase serum protein, undergoing changes in response to intense stress. ${ }^{11}$ A low transthyretin concentration may therefore be considered first as a sign of nutritional risk, which requires prior monitoring and care of the patient. ${ }^{12}$

Given these characteristics, transthyretin has been able to detect nutritional change and determine treatment efficacy and nutritional prognosis, ${ }^{11,13}$ making it an important indicator to screen and diagnose malnutrition, since it is relatively low cost, can be used in the laboratory 
and can be used in various clinical conditions. ${ }^{9,14}$ This work was based on the hypothesis that the transthyretin can to predict malnutrition in cancer patients when compared to the classical methods of nutritional assessment. The objective of this study was to evaluate the association of transthyretin with nutritional status in cancer patients.

\section{Materials and methods}

\section{Study design}

This is a cross-sectional descriptive study, using convenience sampling, performed at a General and Reparatory Surgery and Medical Clinic Unit, between July 2014 and April 2016, at a university hospital in Greater Vitória-ES/Brazil. Participants of the study were Adult (20 to 59.9years) and elderly ( $\geq 60$ years) patients with a confirmed clinical diagnosis of cancer, who presented serum protein evaluation in medical records and were submitted to nutritional status evaluation in the first 48hours of hospital admission. The exclusion criteria considered in this study were: being nursed in isolation and having a diagnosis of hepatic and renal cancer, in order to minimize the influences in the analysis of serum proteins.

After those patients who met the criteria for inclusion had signed an informed consent form, clinical, biochemical and sociodemographic data were collected from the information available in the medical records, followed by anthropometric evaluation at the bedside and administration of the SGA. The diagnosis of malnutrition obtained from transthyretin was compared with the results obtained from the SGA, anthropometric parameters and nutritional markers.

\section{Nutritional assessment}

The anthropometric evaluation was performed by previously trained evaluators, and consisted of body weight $(\mathrm{Kg})$, height $(\mathrm{m})$, arm circumference $(\mathrm{AC})$ and calf circumference $(\mathrm{CC})$ in centimeters, triceps skinfold (TSF) in millimeters, thickness of the adductor pollicis muscle (TAPM) and body mass index (BMI) $\left(\mathrm{kg} / \mathrm{m}^{2}\right)$. The BMI was calculated from the formula: current weight $(\mathrm{kg}) /$ height $2(\mathrm{~m})$. All measurements were performed as recommended by Lohman et al. ${ }^{15}$

The weight was measured by a portable digital scale Techine ${ }^{\circledR}$ Mod. BAL-180 BR with 100gr of graduation and maximum of $180 \mathrm{~kg}$. The height was measured by means of a Personal Caprice Sanny ${ }^{\circledR}$ Estadiometer with a maximum height of $210 \mathrm{~cm}$. The circumference measurements were performed with a tape measure of non-elastic material and length of up to $150 \mathrm{~cm}$. For TSF and TAPM measurements, a Lange Scientific Adipometer ${ }^{\circledR}$ with a precision and sensitivity of $0.1 \mathrm{~mm}$ and reading width of $85 \mathrm{~mm}$ was used.

Subsequently, the arm muscle circumference (ACM) in centimeters and corrected arm muscle area (CAMA) in square centimeters, were determined. For the classification of ACM and CAMA, the percentile values proposed by Frisancho ${ }^{16}$ were used to evaluate the adequacy percentage. For the TAPM, were used. The reference values proposed by Bragagnolo et al. ${ }^{17}$

SGA was used as the gold standard for the diagnosis of nutritional status. Studies in cancer patients have used this method. ${ }^{18,19}$ The SGA includes aspects of the clinical history, such as weight changes, changes in food intake, presence of gastrointestinal symptoms, changes in functional capacity, physical examination, loss of subcutaneous fat and muscle mass, presence of sacral and ankle edema and ascites. The results are expressed in three categories: well-nourished patients
(SGA "A"), suspected/moderate malnutrition (SGA "B") or severely malnourished (SGA “C”). ${ }^{20}$

\section{Biochemical evaluation}

For the biochemical evaluation, the serum concentrations of C-reactive protein (CRP), albumin and transthyretin, which were available in the medical record, were analyzed. All the tests were performed by the laboratory of the hospital where the research was carried out. The classification of nutritional status from transthyretin was performed in this study based on the reference values proposed by Shenkin. ${ }^{21}$ Thus, patients with transthyretin $>17 \mathrm{mg} / \mathrm{dL}$, with moderate risk of malnutrition between $\leq 17$ and $\geq 10 \mathrm{mg} / \mathrm{dL}$ and severe risk of malnutrition, were classified as well-nourished patients with transthyretin level $>10 \mathrm{mg} / \mathrm{dL}$.

\section{Statistical analysis}

For data analysis, serum transthyretin concentrations were grouped into two categories: well-nourished (transthyretin $>17 \mathrm{mg} /$ dL) and malnourished (transthyretin $\leq 17 \mathrm{mg} / \mathrm{dL}$ ). For serum albumin levels, nutritional status was classified into well-nourished patients (albumin $\geq 3.5 \mathrm{mg} / \mathrm{dL}$ ) and malnourished patients (albumin $\leq 3.5 \mathrm{mg} /$ dL). Means and standard deviations were used to describe the continuous and percentage variables for the categorical variables. The Kolmogorov-Smirnov test was used to verify the normality of the quantitative variables. Nonparametric two-tailed tests were applied when necessary. For comparison of two means, the Student's t- test and the nonparametric Mann-Whitney test were used. To verify the presence of a correlation between the variables, Pearson and Spearman correlations were used according to the normality of the data. The correlation coefficients can vary from -1 to +1 and are categorized as weak $(r<0.3)$, moderate $(r=0.3-0.7)$ or strong $(r>0.7) .{ }^{22}$

\section{Ethical considerations}

This study was approved by the Ethics and Research Committee of the Federal University of Espirito Santo, under the number CAAE 27954014.0.0000.5060.

\section{Results}

Seventy patients were evaluated. The mean age was $58.51 \pm 14.85$ years, $51.4 \%(\mathrm{n}=36)$ were elderly and female. Regarding the location of the cancer, the lower gastrointestinal tract was most affected, with $42.9 \%(n=30)$ cases, followed by upper gastrointestinal cancer, present in $30.0 \%(\mathrm{n}=21)$ of the patients. Bladder and soft tissue cancer were grouped in the other category (Table 1).

Figure 1 shows the prevalence of SGA malnutrition, serum transthyretin and serum albumin levels. SGA, transthyretin and serum albumin identified the presence of malnutrition in $71.56 \%(\mathrm{n}=50)$, $50.0 \%(n=35)$ and $32.9 \% \quad(n=23)$, respectively. There were no significant differences between them (SGA $x$ transthyretin, $p=0,237$, SGAx albumin: 0.220).

Table 2 shows the averages of the anthropometric and biochemical variables according to the groups with and without nutritional risk, classified from the values of transthyretin. Significant differences were found for AC variables ( $p=0.011)$ and CAMA $(p=0.012)$. It is worth noting that CRP levels did not differ statistically between the groups with and without nutritional risk, suggesting that transthyretin levels were not influenced by inflammation. 
Table I Sample distribution according to demographic variables, tumor location and nutritional status

\begin{tabular}{|c|c|c|c|c|}
\hline \multicolumn{5}{|c|}{ Transthyretin } \\
\hline Variable & $\mathrm{N}=70$ & $\begin{array}{l}>17,0 \mathrm{mg} / \mathrm{dl} \text { Without } \\
\text { risk nutritional }\end{array}$ & $\begin{array}{l}\leq 17,0 \mathrm{mg} / \mathrm{dl} \text { With } \\
\text { risk nutritional }\end{array}$ & $p$ value \\
\hline Age & $58.5 I \pm 14.85$ & $56.48 \pm 16.71$ & $60.54 \pm 12.64$ & 0.256 \\
\hline Sex & $N(\%)$ & $N(\%)$ & $\mathrm{N}(\%)$ & \multirow{3}{*}{0.093} \\
\hline Male & $34(48,6)$ & $22(61.1)$ & 14(38.9) & \\
\hline Female & $36(51.4)$ & 13(38.2) & $21(61.8)$ & \\
\hline \multicolumn{5}{|l|}{ Life stage } \\
\hline Adult & $34(48.6)$ & $19(55.9)$ & $15(44.1)$ & \multirow{2}{*}{0.473} \\
\hline Elderly & $36(5 I .4)$ & $16(44.4)$ & $20(55.6)$ & \\
\hline \multicolumn{5}{|l|}{ Tumor location } \\
\hline Upper GI & $21(30.0)$ & $12(57.1)$ & 09(42.9) & \multirow{6}{*}{0.211} \\
\hline Lower GI & $30(42.9)$ & $16(53.3)$ & $14(46.7)$ & \\
\hline Pancreas & $07(10.0)$ & $02(28.6)$ & 05(7I.4) & \\
\hline Bile ducts & $05(7.10)$ & $04(80.0)$ & OII(20.0) & \\
\hline Lung & $03(4.30)$ & - & $03(100.0)$ & \\
\hline Others & $04(5.70)$ & 이(25.0) & $03(75.0)$ & \\
\hline \multicolumn{5}{|l|}{ SGA } \\
\hline Well-nourished (A) & $20(28.6)$ & |4(70.0) & $06(30.0)$ & \\
\hline $\begin{array}{l}\text { Suspected/Moderate } \\
\text { malnourished (B) }\end{array}$ & $23(32.9)$ & $08(34.8)$ & $15(65.2)$ & 0.66 \\
\hline Severe malnourished $(C)$ & $27(38.6)$ & $13(48.1)$ & $14(5 \mid .9)$ & \\
\hline
\end{tabular}

$\mathrm{Gl}$, gastrointestinal tract; SGA, subjective global assessment

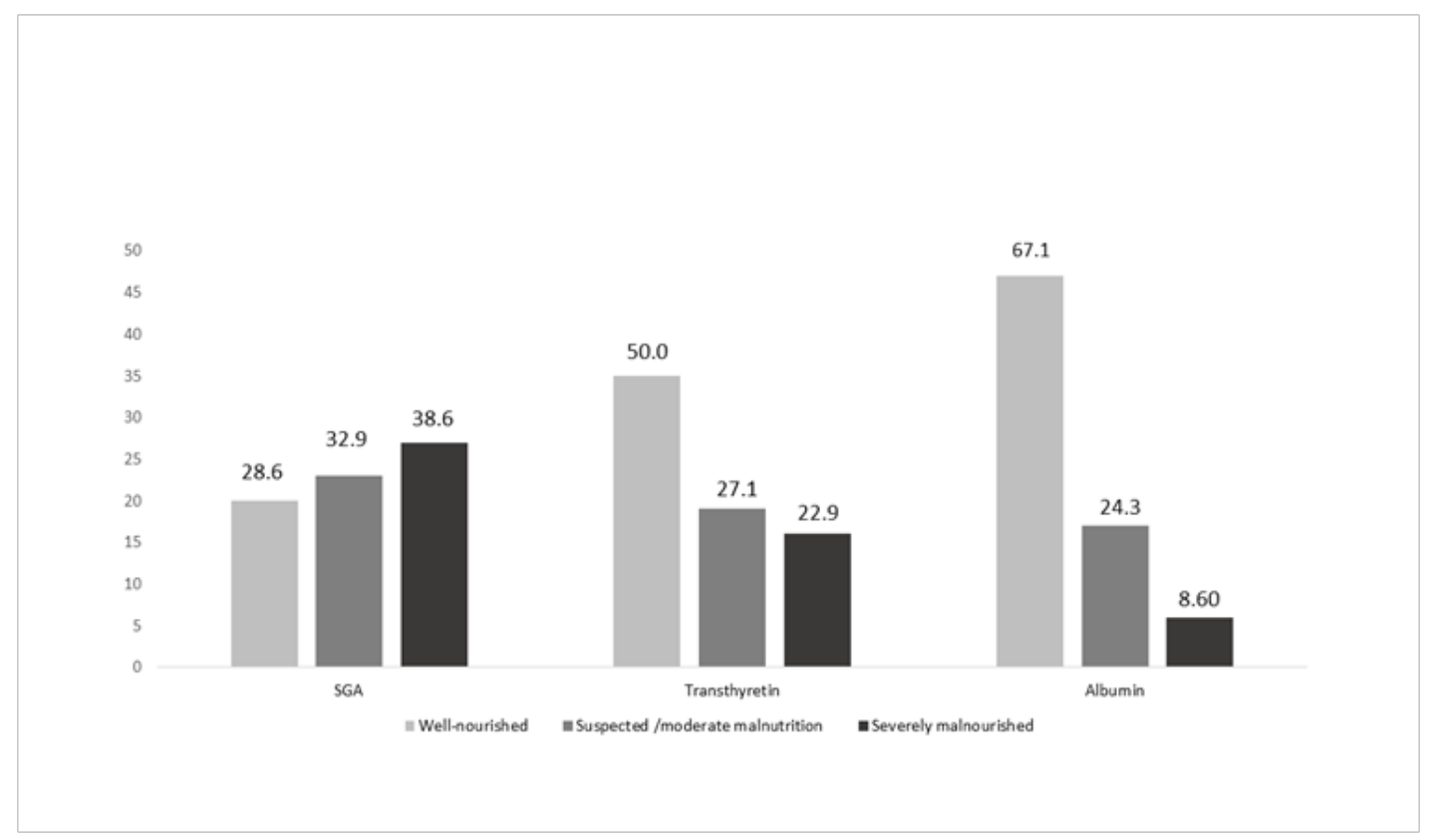

Figure I Prevalence of malnutrition in cancer patients from Global Subjective Assessment, serum transthyretin and albumin. 
Table 2 Comparison of anthropometric and biochemical variables according to transthyretin categories

\begin{tabular}{|c|c|c|c|}
\hline \multicolumn{4}{|c|}{ Transthyretin } \\
\hline Variable & > I7,0mg/dI Without risk Nutritional & $\leq 17,0 \mathrm{mg} / \mathrm{dl}$ With risk nutritional & p value \\
\hline $\mathrm{CC}(\mathrm{cm})^{\mathrm{b}}$ & $33.71 \pm 3.89$ & $28.49 \pm 4.18$ & 0.173 \\
\hline$A C(\mathrm{~cm})^{\mathrm{a}}$ & $28.49 \pm 4.18$ & $25.90 \pm 4.03$ & $0.011 *$ \\
\hline $\mathrm{TSF}(\mathrm{mm})^{\mathrm{a}}$ & $|5.7| \pm 6,76$ & $12.42 \pm 7.18$ & 0.053 \\
\hline $\operatorname{TAPM}(\mathrm{mm})^{\mathrm{a}}$ & $14.90 \pm 4.40$ & $14.10 \pm 5.39$ & 0.494 \\
\hline CAMA $(\mathrm{cm} 2)^{\mathrm{a}}$ & $37.50 \pm 13.33$ & $30.59 \pm 8.71$ & $0.012^{*}$ \\
\hline $\operatorname{ACM}(\mathrm{cm})^{\mathrm{a}}$ & $23.37 \pm 3.63$ & $21.90 \pm 2.52$ & 0.076 \\
\hline BMI $(\mathrm{kg} / \mathrm{m} 2)^{\mathrm{a}}$ & $23.26 \pm 4.49$ & $23.20 \pm 4.74$ & 0.958 \\
\hline Albumin $(\mathrm{mg} / \mathrm{dL})^{\mathrm{a}}$ & $3.64 \pm 0.44$ & $3.63 \pm 0,46$ & 0.935 \\
\hline $\mathrm{CRP}(\mathrm{mg} / \mathrm{dL})^{\mathrm{b}}$ & $23.35 \pm 29.37$ & $39.02 \pm 52.51$ & 0.344 \\
\hline
\end{tabular}

${ }^{\text {aS }}$ tudent $\mathrm{T}$ test; ${ }^{\mathrm{b}}$ Mann-Whitney test

CC, calf circumference, AC, arm circumference;TSF, triceps skinfold;TAPM, thickness of the adductor pollicis muscle; ACM, arm muscle area; CAMA, corrected arm muscle area; BMI, body mass index; CRP, C-reactive protein. ${ }^{*} \mathrm{p}<0.05$

Correlations between transthyretin and anthropometric and biochemical variables are described in Table 3. Although significant, there was a weak correlation between transthyretin and $\mathrm{AC}(\mathrm{p}=0.019)$, while moderate correlations were found with ACM variables $(\mathrm{p}=0.008)$, CAMA $(\mathrm{p}=0.001)$ and albumin $(\mathrm{p}<0.00)$

Table 3 Correlation between serum transthyretin concentrations, anthropometric and biochemical variables

\begin{tabular}{lll}
\hline Variable $(\mathbf{n}=70)$ & $\mathbf{r}$ & p value \\
\hline $\mathrm{CC}(\mathrm{cm})^{\mathrm{a}}$ & 0.194 & 0.107 \\
$\mathrm{AC}(\mathrm{cm})^{\mathrm{a}}$ & 0.286 & $0.025^{*}$ \\
TSF $(\mathrm{mm})^{\mathrm{a}}$ & 0.022 & 0.857 \\
TAPM $(\mathrm{mm})^{\mathrm{a}}$ & 0.072 & 0.569 \\
ACM $(\mathrm{cm})^{\mathrm{a}}$ & 0.312 & $0.008^{* *}$ \\
CAMA $(\mathrm{cm} 2)^{\mathrm{a}}$ & 0.382 & $0.001 * *$ \\
BMI $(\mathrm{kg} / \mathrm{m} 2)^{\mathrm{a}}$ & -0.7 & 0.554 \\
Albumin $(\mathrm{mg} / \mathrm{dL})^{\mathrm{a}}$ & 0.011 & 0.93 \\
CRP $^{\mathrm{b}}(\mathrm{mg} / \mathrm{dL})^{\mathrm{b}}$ & -0.116 & 0.34
\end{tabular}

aPearson's correlation; 'bperman correlation; ${ }^{*} \mathrm{p}<0,05 *$; ${ }^{*} \mathrm{p}<0,0$;

CC, calf circumference, AC, arm circumference; TSF, triceps skinfold; TAPM, thickness of the adductor pollicis muscle; ACM, arm muscle area; CAMA, corrected arm muscle area; BMI, body mass index; CRP, C-reactive protein

When compared to SGA, transthyretin exhibited sensitivity of $58.0 \%$ and specificity of $70.0 \%$. The positive predictive value (PPV) was $83.0 \%$ and the negative predictive value (NPV) was $40.0 \%$. The accuracy of the test was $61.0 \%$.

\section{Discussion}

The findings of the present study showed the association of transthyretin with the anthropometric variables used to evaluate nutritional status, especially those that evaluate the reduction of energy and protein reserves, such as AC, ACM and CAMA. Although transthyretin was not associated with SGA and serum albumin, a reduction in its concentrations was observed with the worsening nutritional status, indicated by categories B and C of SGA. Patients with cancer present with rapid weight loss and the presence of early malnutrition, not always occurring concomitantly. Weight loss may not be the first sign of malnutrition, which reaffirms the need for early markers of nutritional status, such as transthyretin. ${ }^{23}$

The decline of serum proteins is associated with a higher incidence of morbidity and mortality in cancer patients. ${ }^{24}$ Reduced levels of these proteins may be related primarily to nutritional changes, as well as being sensitive to nutritional intervention, since they have a high capacity for hepatic synthesis in the presence of protein intake. ${ }^{25,26}$ Unlike transthyretin, serum albumin is not able to assess acute changes in nutritional status due to its long half-life, which is more adequate for chronic malnutrition, ${ }^{27}$ corroborating the results of this study, in that normal albumin values were present even in the groups with low transthyretin levels.

As for anthropometric parameters, they are unable to detect recent disturbances of nutritional status, and therefore, when applied alone, do not reflect the patient's actual nutritional status. ${ }^{28,29}$ Our results showed that despite significant results, AC, ACM and CAMA presented, respectively, a weak and moderate correlation with serum transthyretin levels. Thus, the use of transthyretin may be a complementary tool in the initial assessment of nutritional status. ${ }^{4,26,30}$

Transthyretin has also been recognized as a possible preoperative risk marker and infection, ${ }^{30}$ by anticipating the acute phase response and thus allowing the nutritional strategy to be traced at this stage. ${ }^{9}$

The hospitalized patient presents several clinical conditions that, in addition to malnutrition, affect serum proteins. Devoto et al. ${ }^{26}$ found a correlation between nutritional status and transthyretin, independently of the concentrations of CRP, a condition observed in this study.

Although the majority of patients with nutritional risk have low 
levels of transthyretin, the low specificity attributes low diagnostic value to this tool. Diseases that cause proteinuria and exacerbate acute phase response, such as neoplasms, may be responsible for the increase in the false positive. ${ }^{31}$

Studies of patients diagnosed with head and neck cancer ${ }^{18}$ and esophageal cancer submitted to radiotherapy ${ }^{19}$ obtained significantly lower levels of transthyretin in malnourished patients, as defined by SGA, when compared to well-nourished patients. In contrast, albumin did not present a significant difference between nutritional status and between groups at the beginning and end of radiotherapy.

Given its limitations and applications, the use of transthyretin as a complement to the classic nutritional status assessment methods is suggested, with the aim of providing a more complete and careful evaluation, as well as to identify patients at nutritional risk early, and to plan and follow-up nutritional intervention.

Among the limitations of this study, it is emphasized that caution is required in the interpretation of biochemical tests as a function of factors such as perioperative fasting, hemodilution, renal diseases and tumor staging that may have affected levels of transthyretin in the blood. In addition, it should be noted that this study involved only cancer patients, a fact that limits the extrapolation of the results.

\section{Conclusion}

Transthyretin was moderately associated with the anthropometric variables arm circumference and corrected arm muscle area which represents the energy and muscle mass reserves. The results show the difficulty of using transthyretin in the diagnosis of malnutrition in the cancer patient, since it is influenced by several factors present in these individuals. However, transthyretin may be a complementary tool in the initial nutritional assessment, because it is feasible, easy to interpret and undergoes changes in a short period.

\section{Acknowledgments}

Special thank you goes to the University Hospital Cassiano Antônio Moraes for all support and assistance throughout the research and Health Sciences Centre/Federal University of Espirito Santo.

\section{Conflict of interest}

The author declares that there is no conflict of interest.

\section{References}

1. Waitzberg DL, Caiaffa WT, Correia MI. Hospital malnutrition: the Brazilian national survey (IBRANUTRI): a study of 4000 patients. Nutrition. 2001;17(7-8):573-80.

2. National Cancer Institute José Alencar Gomes da Silva (INCA). Brazilian Enquiry on Oncology Nutrition. Rio de Janeiro. 2013. 136p.

3. Barthelemy N, Streel S, Donneau AF, et al. Screening for malnutrition in lung cancer patients undergoing radiotherapy. Support Care Cancer. 2014;22(6):1531-6.

4. Luis DA, Torroba MC, Cuellar L, et al. Association of anthropometric and biochemical markers with length of stay and mortality in the hospital. Eur Rev Med Pharmacol Sci. 2013;17(10):1321-5.

5. Felder S, Lechtenboehmer C, Bally M, et al. Association of nutritional risk and adverse medical outcomes across different medical inpatient populations. Nutrition. 2015;31:1385-1393.
6. Silva FR, Oliveira MG, Souza AS, et al. Factors associated with malnutrition in hospitalized cancer patients: a cross-sectional study. Nutr J. 2015;14:123.

7. National Cancer Institute José Alencar Gomes da Silva (INCA). National Consensus Oncology Nutrition. Rio de Janeiro; 2015. 186p.

8. Correira MA, Santos C, Almeida B, et al. Scored patient-generated subjective global assessment, albumin and transferrin for nutritional assessment of gastrostomy fed head or neck cancer patients. Nutr Hosp. 2014;29(2):420-426.

9. Delliere S, Cynober L. Is transthyretin a good marker of nutritional status? Clinical Nutrition. 2017;36(2):364-370.

10. Lee HK, Cho JH, Kwon O, et al. Low prealbumin levels are independently associated with higher mortality in patients on peritoneal dialysis. Kidney Res Clin Pract. 2016;35(3):169-175.

11. Li B, Liu H, Guo S, et al. Impact of early enteral and parenteral nutrition on prealbumin and high-sensitivity C-reactive protein after gastric surgery. Genetics and Molecular Research. 2015;14(2):7130-7135.

12. Aydın Y, Kaplan I, Gündoğdu B, et al. Prognostic importance of serum CRP, prealbumin, and transferrin levels in patients with advanced stage esophageal cancer. Türk Gögüs Kalp Damar Cer Derg. 2011;19(3):384-390.

13. Hur H, Kim SG, Shim JH, et al. Effect of early oral feeding after gastric cancer surgery: a result of randomized clinical trial. Surgery. 2015;149(4):561-568.

14. Frederick K, Beck M, Thomas C, et al. Prealbumin: A Marker for Nutritional Evaluation. Am Fam Physician. 2002;65(8):1575-1579.

15. Lohman TG, Roche AF, Martorell R. Anthropometric standardization reference manual. Champaign: Human Kinetics. 1988.

16. Frisancho AR. Anthropmetric standarts for the assessment of growth andnutrition status. Michigan: University of Michigan Press; 1990. p. 189.

17. Bragagnolo R, Caporossi FS, Dock-Nascimento DB, et al. Adductor pollicis muscle thickness: a fast and reliable method for nutritional assessment in surgical patients. Rev Col Bras Cir. 2009;36(5):371-376.

18. Unal D, Orhan O, Eroglu C, et al. Prealbumin is a more sensitive marker than albumin to assess the nutritional status in patients undergoing radiotherapy for head and neck cancer. Contemp Oncol (Pozn). 2013;17(3):276-280.

19. Pan P, Tao G, Sun X. Subjective global assessment and prealbumin levels of esophageal cancer patients undergoing concurrent chemoradiotherapy. Nutr Hosp. 2015;31(5):2167-2173.

20. Detsky AS, McLaughlin JR, Baker JP, et al. What is subjective global assessment of nutritional status? JPEN J Parenter Enteral Nutr. 1987;11(1):8-13.

21. Shenkin A. Serum prealbumin: Is it a marker of nutritional status or of risk of malnutrition? Clin Chem. 2006;52(12):2177-2179.

22. Willett WC. Nutritional epidemiology. 2nd ed. New York: Oxford University Press; 1998.

23. Sarhill N, Mahmoud FA, Christie R, et al. Assessment of nutritional status and fluid deficits in advanced cancer. Am J Hospice Palliat Care. $2003 ; 20(6): 465-73$.

24. Cacicedo J, Casquero F, Martinez-Indart L, et al. Detection of risk factors that influence weight loss in patients undergoing radiotherapy. Rep Pract Oncol Radiother. 2012;17(5):269-275. 
25. Bernstein LH, Ingenbleek Y. Transthyretin: its response to malnutrition and stress injury. Clinical usefulness and economic implications. Clin Chem Lab Med. 2002;40(12):1344-48.

26. Devoto G, Gallo F, Marchello C, et al. Prealbumin Serum Concentrations as a Useful Tool in the Assessment of Malnutrition in Hospitalized Patients. Clinical Chemistry. 2006;52(12):2281-2285.

27. Hasselmann M, Alix E. Tools and procedures for screening for malnutrition and its associated risks in hospital. Nutr Clin Metabol. 2003;17(4):218-226.

28. Fontoura C, Cruz D, Londero L. Nutritional Assessment of the Critical ill Patient. Rev Bras Ter Intensiva. 2006;18:298-306.
29. Fruchtenicht A, Poziomyck A, Kabke G, et al. Nutritional risk assessment in critically ill cancer patients: systematic review. Rev Bras Ter Intensiva. $2015 ; 27(3): 274-283$.

30. Saka B, Uzun S, Erten N, et al. Nutritional risk in hospitalized patients: impact of nutritional status on serum prealbumin. Rev Nutr. 2011;24(1):89-98.

31. Salvetti D, Tempel Z, Gandholke G, et al. Preoperative prealbumin level as a risk factor for surgical site infection following elective spine surgery. Surg Neurol Int. 2015;6(Supp1 19):S500-503. 